\title{
Association of miRNA - 320 expression level and its target gene endothelin-1 with the susceptibility and clinical features of polycystic ovary syndrome
}

Nearmeen M. Rashad ${ }^{1 *}$, Marwa Abdel-Monem Ateya ${ }^{2}$, Yasser S. Saraya ${ }^{3}$, Walid Mohamed Elnagar ${ }^{3}$, Khaled Fathy Helal ${ }^{3}$, Mohamed El-Bakry Lashin ${ }^{3}$, Amr Ahmed Abdelrhman ${ }^{3}$, Ayman E. Alil $^{1}$ and Mohammed S. Yousef ${ }^{1}$

\begin{abstract}
Background: Polycystic ovary syndrome (PCOS) is a common reproductive endocrine disorder characterized by obesity, hyperandrogenism, and insulin resistance (IR). MicroRNAs (miRNAs) are small noncoding RNA associated with ovarian follicle development and female fertility. The objective of this study was to investigate the role of miRNA- 320 and its target gene endothelin-1 (ET-1) as a noninvasive biomarker of PCOS and to evaluate its possible relationship with IR as well as clinic-morphological features of PCOS.

Methods: Case-control study enrolled 60 patients with PCOS and 40 control group. We subdivided our PCOS women according to homeostasis model assessments of insulin resistance (HOMA-IR) to PCOS women with and without IR.ET-1 levels were measured by ELISA. We estimated the serum expression level of miRNA- 320 by real-time polymerase chain reaction.

Results: Our results revealed that serum miR-320 expression level was lower in PCOS patients compared to controls, in particular, PCOS women with IR. Moreover, it was negatively correlated to its target gene; ET-I as well as fasting serum insulin (FSI), HOMA-IR, PCOS phenotype; hirsutism score, ovarian volume and antral follicle count (AFC). In the PCOS group, linear regression analysis revealed that only hirsutism and HOMA-IR was the main predictor of expression levels of miRNA - 320 among other clinical and laboratory biomarkers of PCOS. The sensitivity and specificity of serum miR-320 expression levels in diagnosis PCOS was 80, and $97.5 \%$ respectively.
\end{abstract}

Conclusion: The Expression serum levels of miR-320 were lower in PCOS compared to control and it could be a noninvasive diagnostic biomarker of PCOS.

Keywords: miR-320, PCOS, Gene expression, ET-1, Insulin resistance

\section{Introduction}

Compelling evidence suggests that polycystic ovary syndrome (PCOS) is the commonest reproductive endocrine disease of women as affecting $5-10 \%$ of women in reproductive age [1]. Several lines of evidence indicate that PCOS patients suffer from metabolic disorders, which is manifested by obesity, type 2 diabetes

\footnotetext{
*Correspondence: nrashad78@yahoo.com; n.rashad@zu.edu.eg ${ }^{1}$ Internal Medicine Department, Faculty of Medicine, Zagazig University, Zagazig, Egypt

Full list of author information is available at the end of the article
}

mellitus(T2DM) and insulin resistance (IR), in this respect, about $50-70 \%$ of PCOS patients have various degree of IR [2]. A growing body of evidence has corroborated the association between IR and hyperandrogenism among PCOS women [3].

MicroRNAs (miRNAs) are small, non-coding RNAs (19-23 nucleotides) that inhibit translation and/or direct mRNA degradation, in addition they have an autocrine and endocrine regulatory function of gene expression and involved in the pathogenesis of complex diseases including obesity [4], T2DM [5], and PCOS [6, 7]. 
MiR-320 has been shown to be involved in growth, proliferation, and the cell cycle by targeting different genes in different cell lines [8]. However, the functions and mechanisms of miR-320 in PCOS remain unclear. MiR-320 is supposed to have widespread biological effects as it regulates multiple important molecules in particular endothelin (ET-1). Mounting evidence indicates that MiR-320 target gene; ET is a bioactive peptide produced by endothelial cells that can promote cell mitosis, participate in tumor growth and induce mitosis in tumor growth [9]. Three types of ET have been identified, ET-1, ET-2, and ET-3, of which ET-1 is the most potent biomolecule [10].

Emerging evidence demonstrated that genetic factors in PCOS pathogenesis, of particular interest the genes that are involved in the etiology of the syndrome have not been fully investigated until now, as well as the environmental contribution in their expression. The aim of the current study was to investigate the role of miRNA- 320 as a noninvasive biomarker of PCOS and to evaluate its possible relationship with IR as well as clinic-morphological features of PCOS.

\section{Materials and methods}

This case-control study included 100 unrelated subjects. Sixty women with PCO recruited from Outpatient Clinics of the Endocrinology Unit of Internal Medicine and Obstetrics and Gynecology Departments, Faculty of Medicine, Zagazig University, Egypt and 40 healthy women matched to PCOS women as regard age, and ethnic origin. Patients were divided into two groups; PCOS without IR [(homeostatic model assessment-IR) HOMA -IR <2.11), $n=35$ ] and PCOS with IR [(HOMA -IR > 2.11), $n=25$ ]. The diagnosis of PCOS was based on the 2004 revised Rotterdam criteria [11]. All women underwent a menstrual history and a thorough clinical examination. All patients were subjected to thorough history taking, full clinical assessment and anthropometric measures of obesity. Ovarian volume and antral follicular count were evaluated by transvaginal ultrasound (TVS). The exclusion criteria for all women included a history of hyperandrogenic states (such as non-classical congenital adrenal hyperplasia, androgen-secreting tumors, Cushing's syndrome, 21-hydroxylase deficiency, or hyperprolactinemia), hypertension, liver, kidney, or thyroid diseases.

\section{Ethics approval and consent to participate}

Written informed consent was taken from all of the participants. The ethical committee of Faculties of Medicine, Zagazig University approved this study.

\section{The sampling of blood and laboratory assessments}

Blood samples were drawn from all subjects during the early follicular phase of the menstrual cycles after an overnight fast. Fasting plasma glucose (FPG), total cholesterol (TC), high-density lipoprotein (HDL) cholesterol, triglycerides level and low-density lipoprotein (LDL) cholesterol level were determined using automated analyzer (Roche Cobas 8000-c702, Roche Diagnostics, Germany).

Serum ET-1 levels were estimated using a quantitative sandwich ELISA method according to manufacturer's instructions (R\& D Minneapolis, MN, USA) ELISA kit. We measured, fasting serum insulin (FSI), follicle stimulating hormone (FSH), luteinizing hormone (LH), total testosterone, we calculated insulin resistance (IR) with the HOMA-IR index, which is defined as the FSI value $(\mathrm{lU} / \mathrm{mL}) \times \mathrm{FPG}$ value $(\mathrm{mg} / \mathrm{dl}) / 405$. The $\beta$-cell function was calculated using HOMA- $\beta$ as follows: $\{20 *[\mathrm{FSI}(\mu \mathrm{U} / \mathrm{mL})] /[\mathrm{FPG}(\mathrm{mmol} / \mathrm{L})-3.5]\}$. the laboratory

Table 1 Clinical, anthropometric and laboratory characteristics of studied groups

\begin{tabular}{|c|c|c|c|}
\hline & $\begin{array}{l}\text { Control group } \\
\text { (mean } \pm S D) \\
(n=40)\end{array}$ & $\begin{array}{l}\text { PCO patients } \\
\text { (mean } \pm \text { SD) } \\
(n=60)\end{array}$ & P \\
\hline $\begin{array}{l}\text { Systolic blood pressure } \\
(\mathrm{mm} \mathrm{Hg})\end{array}$ & $125.4 \pm 7.16$ & $130.6 \pm 7.3$ & $<0.001^{*}$ \\
\hline $\begin{array}{l}\text { Diastolic blood pressure } \\
(\mathrm{mm} \mathrm{Hg})\end{array}$ & $85.6 \pm 3.96$ & $87.5 \pm 4.9$ & $<0.001^{*}$ \\
\hline Hirsutism score & $5.38 \pm 0.594$ & $7.41 \pm 3.02$ & $<0.001^{*}$ \\
\hline Body mass index (kg/m2) & $24.9 \pm 2.48$ & $33.2 \pm 5.731$ & $<0.001^{*}$ \\
\hline Waist/hip ratio & $0.98 \pm 0.191$ & $1.26 \pm 0.28$ & $<0.001^{*}$ \\
\hline Ovarian volume & $3.58 \pm 0.612$ & $7.35 \pm 2.744$ & $<0.001^{*}$ \\
\hline AFC & $2.58 \pm 0.612$ & $7.35 \pm 2.744$ & $<0.001^{*}$ \\
\hline Total cholesterol (mg/dL) & $167.5 \pm 19.26$ & $185.0 \pm 124.7$ & $<0.001^{*}$ \\
\hline Triglycerides (mg/dL) & $144.55 \pm 20.4$ & $192.2 \pm 42.05$ & $<0.001^{*}$ \\
\hline LDL cholesterol (mg/dL) & $106.24 \pm 4.24$ & $125.8 \pm 18.11$ & $<0.001^{*}$ \\
\hline HDL cholesterol (mg/dL) & $57.5 \pm 7.33$ & $40.3 \pm 9.42$ & $<0.001^{*}$ \\
\hline Fasting plasma glucose (mg/dL) & $83.9 \pm 8.40$ & $95.3 \pm 15.61$ & $<0.001^{*}$ \\
\hline $\mathrm{HbA1c}(\%)$ & $5.5 \pm 0.596$ & $6.03 \pm 0.42$ & $<0.001^{*}$ \\
\hline Fasting serum insulin (IU/mL) & $6.8 \pm 1.44$ & $17.5 \pm 10.41$ & $<0.001^{*}$ \\
\hline HOMA-IR & $1.42 \pm 0.322$ & $3.7 \pm 2.32$ & $<0.001^{*}$ \\
\hline HOMA- $\beta$ & $166.9 \pm 76.9$ & $127.7 \pm 81.84$ & 0.016 \\
\hline $\mathrm{FSH}(\mathrm{mlU} / \mathrm{mL})$ & $4.8 \pm 0.972$ & $5.5 \pm 1.538$ & $<0.001^{*}$ \\
\hline $\mathrm{LH}(\mathrm{mlU} / \mathrm{mL})$ & $5.52 \pm 1.21$ & $6.97 \pm 1.53$ & $<0.001^{*}$ \\
\hline LH/FSH & $1.2 \pm 0.43$ & $13 \pm 0.39$ & 0.145 \\
\hline DHEA-S (mg/mL) & $0.99 \pm 0.31$ & $1.3 \pm 0.77$ & $<0.001^{*}$ \\
\hline Androstenedione (ng/mL) & $1.17 \pm 0.34$ & $1.7 \pm 0.5$ & 0.015 \\
\hline Total testosterone $(\mathrm{ng} / \mathrm{mL})$ & $0.50 \pm 0.145$ & $0.7 \pm 0.32$ & $<0.001^{*}$ \\
\hline
\end{tabular}

FSI fasting serum insulin, FPG fasting plasma glucose, $A F C$ antral follicle cells, HOMA-IR homeostasis model assessments of insulin resistance, DHEA dehydroepiandrosterone, ${ }^{*} P<0.05$ when compared with control group 
assessments were done at the Clinical Pathology Department in Faculty of Medicine, Zagazig University, Egypt.

\section{MicroRNA extraction from sera}

miRNAs were extracted from serum samples of the patients and control subjects using the miRNeasy mini kit (Qiagen, Germany); according to the manufacturer's instructions. The concentrations and purity of the miRNAs were determined using Qubit $^{\circ} 3$ Fluorometer (Thermo Fisher Scientific Inc., USA).

\section{Reverse transcription of mi RNA to complementary DNA}

Reverse transcription reaction was performed using the miScript II RT Kit (Qiagen, Germany) according to the manufacturer's instruction.

\section{Real-time polymerase chain reaction}

Amplification was performed using the Stratagene Mx3005P platform (Agilent Technologies, USA) and QuantiFast SYBR Green PCR Kit, (Qiagen, Germany). Primers design was forward, 5'-ACACTCCAGCTGGG
AAAAGCTGGGTTGAGA-3'; reverse, $\quad 5^{\prime}$ - $\quad$ TGGT GTCGTGGAGTCG-3. The reaction mixture was prepared according to manufacture recommendation with total volume of $20 \mu \mathrm{l}$ : $10 \mu \mathrm{l} 2 \mathrm{x}$ QuantiFast SYBR Green PCR Master Mix, $2 \mu \mathrm{l}$ 10x forward primer, $2 \mu \mathrm{l} 10 \mathrm{x}$ reverse primer, $4 \mu \mathrm{l}$ RNase free water and $2 \mu \mathrm{l}$ of c DNA using the following cyclic condition: initial activation $15 \mathrm{~min}$ at $95^{\circ} \mathrm{C}$ then 40 cycles of $15 \mathrm{~s}$ at $94{ }^{\circ} \mathrm{C}, 30 \mathrm{~s}$ at $55^{\circ} \mathrm{C}$ and $30 \mathrm{~s}$ at $70^{\circ} \mathrm{C}$. Expression values were obtained as the relative gene $(\Delta \mathrm{CT}=$ Target gene $\mathrm{CT}-$ Reference gene CT).

\section{Statistical analysis}

Statistical analyses were performed using the Statistical Package for the Social Sciences (version 21.0; SPSS, Chicago, IL, USA). The comparison between two groups with parametric variables was done using independent sample $\mathrm{t}$-test $(\mathrm{t})$ and nonparametric variables using the Mann-Whitney test (z). Correlation analysis was performed using the Pearson correlation method. Linear regression analyses were done to test the influence of

Table 2 Clinical, anthropometric and laboratory characteristics of studied groups

\begin{tabular}{|c|c|c|c|c|c|c|}
\hline & $\begin{array}{l}\text { Control group } \\
(\text { mean } \pm \text { SD) } \\
(n=40)\end{array}$ & $\begin{array}{l}\text { Non-IR group } \\
(\text { mean } \pm S D) \\
(n=25)\end{array}$ & $\begin{array}{l}\text { IR group } \\
(\text { mean } \pm \text { SD) } \\
(n=35)\end{array}$ & P 1 & P2 & P3 \\
\hline $\mathrm{SBP}(\mathrm{mm} \mathrm{Hg})$ & $125.4 \pm 7.16$ & $126.96 \pm 8.33$ & $133.2 \pm 5.19$ & 0.37 & $<0.001^{*}$ & $<0.001^{*}$ \\
\hline $\mathrm{DBP}(\mathrm{mm} \mathrm{Hg})$ & $85.6 \pm 3.96$ & $86.28 \pm 4.39$ & $88.37 \pm 5.1$ & 0.555 & 0.009 & 0.104 \\
\hline Hirsutism score & $5.38 \pm 0.594$ & $7.34 \pm 4.49$ & $7.45 \pm 1.2$ & $<0.001^{*}$ & $<0.001^{*}$ & 0.893 \\
\hline Body mass index (kg/m2) & $24.9 \pm 2.48$ & $29.1 \pm 5.96$ & $36.18 \pm 3.2$ & $<0.001^{*}$ & $<0.001^{*}$ & $<0.001^{*}$ \\
\hline Waist/hip ratio & $0.98 \pm 0.191$ & $1.11 \pm 0.28$ & $1.36 \pm 0.2$ & $<0.05^{*}$ & $<0.001^{*}$ & $<0.001^{*}$ \\
\hline Ovarian volume & $3.58 \pm 0.612$ & $7.2 \pm 4.56$ & $7.85 \pm 1.437$ & $<0.001^{*}$ & $<0.001^{*}$ & 0.467 \\
\hline AFC & $2.58 \pm 0.612$ & $7.3 \pm 4.02$ & $7.37 \pm 1.285$ & $<0.001^{*}$ & $<0.001^{*}$ & 0.952 \\
\hline Total cholesterol (mg/dL) & $167.5 \pm 19.26$ & $167.1 \pm 25.15$ & $197.8 \pm 14.4$ & 0.916 & $<0.001^{*}$ & $<0.001^{*}$ \\
\hline Triglycerides (mg/dL) & $144.55 \pm 20.4$ & $193.2 \pm 58.2$ & $191.6 \pm 25.9$ & $<0.001^{*}$ & $<0.001^{*}$ & 0.883 \\
\hline LDL cholesterol (mg/dL) & $106.24 \pm 4.24$ & $114.3 \pm 17.4$ & $134.06 \pm 13.6$ & 0.01 & $<0.001^{*}$ & $<0.001^{*}$ \\
\hline HDL cholesterol (mg/dL) & $57.5 \pm 7.33$ & $45.8 \pm 9.27$ & $36.4 \pm 7.48$ & $<0.001^{*}$ & $<0.001^{*}$ & $<0.001^{*}$ \\
\hline Fasting plasma glucose (mg/dL) & $83.9 \pm 8.40$ & $93.7 \pm 16.19$ & $96.4 \pm 15.3$ & $<0.001^{*}$ & $<0.001^{*}$ & 0.516 \\
\hline $\mathrm{HbA1c}(\%)$ & $5.5 \pm 0.596$ & $5.8 \pm 0.171$ & $6.18 \pm 0.49$ & 0.01 & $<0.001^{*}$ & $<0.001^{*}$ \\
\hline Fasting serum insulin (IU/mL) & $6.8 \pm 1.44$ & $7.2 \pm 1.29$ & $24.97 \pm 7.17$ & 0.755 & $<0.001^{*}$ & $<0.001^{*}$ \\
\hline HOMA-IR & $1.42 \pm 0.322$ & $1.65 \pm 0.3$ & $5.25 \pm 1.92$ & 0.448 & $<0.001^{*}$ & $<0.001^{*}$ \\
\hline HOMA- $\beta$ & $166.9 \pm 76.9$ & $149.3 \pm 18.3$ & $86.2 \pm 22.5$ & 0.384 & $<0.001^{*}$ & $<0.001^{*}$ \\
\hline FSH (mIU/mL) & $4.8 \pm 0.972$ & $5.14 \pm 1.27$ & $5.85 \pm 1.65$ & 0.313 & $<0.001^{*}$ & 0.078 \\
\hline LH (mlU/mL) & $5.52 \pm 1.21$ & $6.1 \pm 1.2$ & $7.59 \pm 1.4$ & 0.081 & $<0.001^{*}$ & $<0.001^{*}$ \\
\hline LH/FSH & $1.2 \pm 0.43$ & $7.59 \pm 1.4$ & $1.3 \pm 0.4$ & 0.778 & $<0.001^{*}$ & 0.121 \\
\hline DHEA-S (mg/mL) & $0.99 \pm 0.31$ & $0.99 \pm 0.34$ & $1.5 \pm 0.91$ & 0.967 & $<0.001^{*}$ & $<0.001^{*}$ \\
\hline Androstenedione (ng/mL) & $1.17 \pm 0.34$ & $1.35 \pm 0.48$ & $2.07 \pm 0.46$ & 0.103 & $<0.001^{*}$ & $<0.001^{*}$ \\
\hline Total testosterone (ng/mL) & $0.50 \pm 0.145$ & $0.62 \pm 0.28$ & $0.9 \pm 0.3$ & 0.062 & $<0.001^{*}$ & $<0.001^{*}$ \\
\hline
\end{tabular}

IR; FSI fasting serum insulin, FPG fasting plasma glucose, AFC antral follicle cells, HOMA-IR homeostasis model assessments of insulin resistance,

$D H E A$ dehydroepiandrosterone

${ }^{1}$ Significant $P$ values $(P<0.05)$ when compared non-IR group with control group

${ }^{2}$ Significant $P$ values $(P<0.05)$ when compared IR group with control group ${ }^{3}$ Significant $P$ values $(P<0.05)$ when compared non-IR group with IR group 
the main independent variables against serum miRNA 320 expression levels in PCOS patients. To test the independent variables associated with PCOS logistic regression analyses were performed. Receiver operating characteristic (ROC) analysis was performed to assess the diagnostic power of serum miRNA -320 expression levels. We considered $\mathrm{P}$ to be significant at $<0.05$ with a $95 \%$ confidence interval $(\mathrm{CI})$.
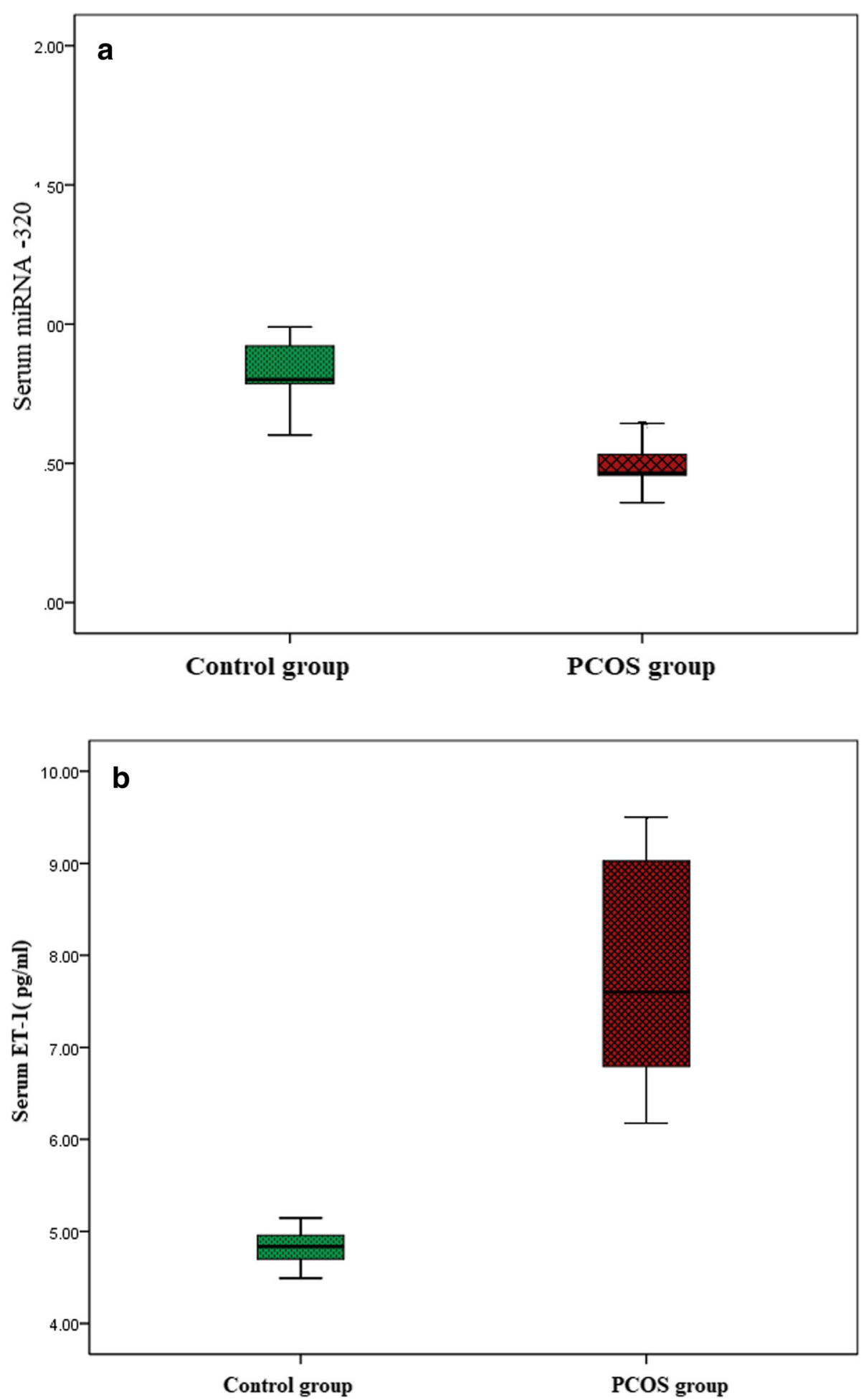

Fig. 1 a Comparison of serum miRNA - 320 expressions levels in studied groups. b Comparison of serum ET-1(pg/ml) in studied groups 


\section{Results}

Among studied patients the mean age of the control group was $32.38 \pm 7.68$ year. While in the PCOS groups the mean age was $31.95 \pm 7.42$. Control and PCOS patients were matched for age and gender. To assess the association of miRNA -320 with IR we subclassified PCOS group to PCOS without IR HOMA -IR $<2.11$ ), and PCOS with IR (HOMA -IR $>2.11$. Comparison of the clinical and laboratory characteristics between patients and control are presented in Table 1.
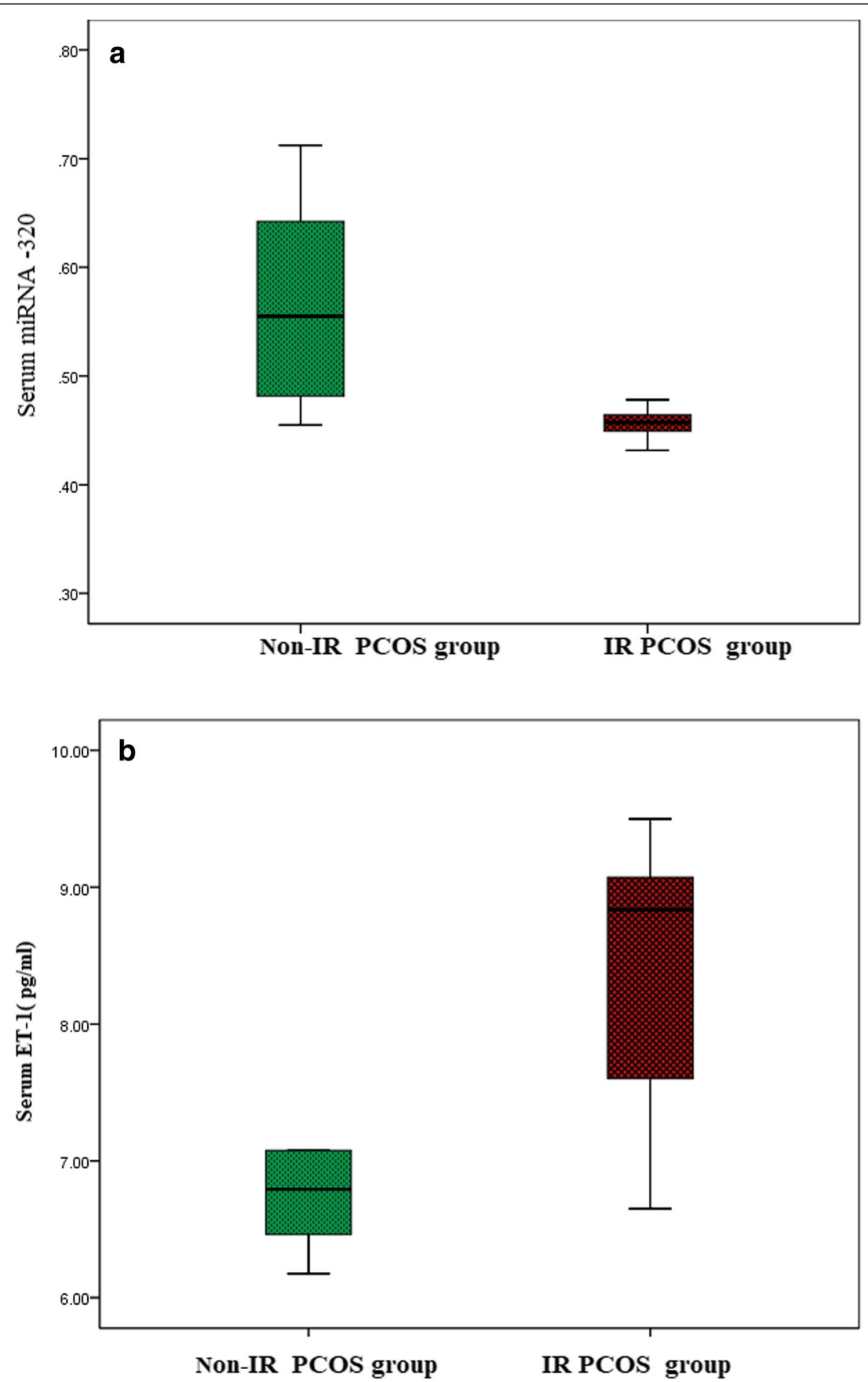

Fig. 2 a Comparison of serum miRNA - 320 expression level in PCOS women. b Comparison of serum ET-1in PCOS women 
Table 3 Pearson correlation of serum miRNA - 320 expression levels with clinical, anthropometric as well as biochemical characteristics in studied subjects

\begin{tabular}{|c|c|c|}
\hline \multirow[t]{2}{*}{ Characteristics } & \multicolumn{2}{|c|}{ Serum miRNA - 320 expression levels } \\
\hline & $r$ & $p$ \\
\hline Hirsutism score & -0.469 & $<0.001^{*}$ \\
\hline Body mass index (kg/m2) & -0.183 & 0.162 \\
\hline Waist/hip ratio & -0.109 & 0.406 \\
\hline Ovarian volume & -0.484 & $<0.001^{*}$ \\
\hline AFC & -0.475 & $<0.001^{*}$ \\
\hline Total cholesterol (mg/dL) & -0.189 & 0.147 \\
\hline Triglycerides (mg/dL) & -0.375 & $<0.001^{*}$ \\
\hline LDL cholesterol (mg/dL) & -0.061 & 0.643 \\
\hline HDL cholesterol (mg/dL) & 0.226 & 0.082 \\
\hline FPG (mg/dL) & -0.020 & 0.882 \\
\hline $\mathrm{FSI}(\mathrm{IU} / \mathrm{mL})$ & -0.515 & $<0.001^{*}$ \\
\hline HOMA-IR & -0.501 & $<0.001^{*}$ \\
\hline $\mathrm{HbA1c}(\%)$ & -0.167 & 0.204 \\
\hline HOMA- $\beta$ & 0.020 & 0.020 \\
\hline Total testosterone $(\mathrm{ng} / \mathrm{mL})$ & 0.098 & 0.456 \\
\hline $\mathrm{FSH}(\mathrm{mlU} / \mathrm{mL})$ & -0.115 & 0.383 \\
\hline $\mathrm{LH}(\mathrm{mlU} / \mathrm{mL})$ & -0.271 & 0.036 \\
\hline DHEA-S (mg/mL) & -0.190 & 0.145 \\
\hline Androstenedione (ng/mL) & -0.207 & 0.112 \\
\hline
\end{tabular}

FSI Fasting serum insulin, FPG Fasting plasma glucose, AFC antral follicle cells, HOMA-IR homeostasis model assessments of insulin resistance, DHEA-S dehydroepiandrosteron sulfate, ${ }^{*}$ Statistically significant $(P<0.05)$

\section{Clinical and laboratory characteristics of studied group}

As expected, our study revealed that there were significantly higher values of PCOS phenotype features in both PCOS groups especially IR group as compared to control group. In addition, IR group had significantly higher values of hyperlipidemia and hyperglycemia compared to control group as shown in Table 2, $p<0.001$. Among the PCOS group, IR patients had significantly higher values of body composition parameters; body mass index (BMI) and waist/hip ratio. Also, systolic blood pressure as well as, TC, LDL, FSI, HbA1c, and HOMA-IR compared to PCOS women without IR. In addition, PCOS phenotypes; LH, DHEA-S androstenedione, and total testosterone, were significantly high in IR patients compared to PCOS women without IR. On the contrary, we detected significant lower HDL and HOMA- $\beta$ levels in the IR group compared to PCOS women without IR, Table $2 P<0.001^{*}$.

\section{Comparison of serum miRNA - 320 expression and serum $\mathrm{ET}-1(\mathrm{pg} / \mathrm{ml})$ in studied groups}

Regarding expression levels of miRNA -320, PCOS patients $(0.91 \pm 0.331)$ had significantly lower levels compared to the control group $(0.49 \pm 0.08))$ Fig. 1a). Among the PCOS group, IR patients $(0.456 \pm 0.034)$ had significantly lower expression levels of miRNA - 320 compared to PCOS women without IR $(0.558 \pm 0.084)$ (Fig. 1b), $P<0.001^{*}$.

Regarding serum levels of ET-1, PCOS patients $(7.86 \pm 1.133)$ had significantly higher levels compared to the control group $(4.82 \pm 0.193)$ (Fig. 2a). Among the PCOS group, IR patients $(8.27 \pm 0.876)$ had significantly higher serum levels of ET-1compared to PCOS women without IR (7.14 \pm 0.876$)$ (Fig. $2 b), P<0.001^{*}$.

\section{Correlation between expression levels of miRNA - 320 with clinical and biochemical parameters of PCOS patients}

Serum miRNA - 320 expression levels were significantly negatively correlated with FSI and HOMA-IR, as well as PCOS phenotype; hirsutism score, ovarian volume AFC, and TG. Even more interestingly, miRNA - 320 expression levels were significantly negatively correlated ET-1 with $P<0.001^{*}$, (Table 3 ).

Table 4 linear regression analyses in PCOS women to test the influence of the main independent variables against serum miRNA -320 expression levels (dependent variable) in PCOS women

\begin{tabular}{|c|c|c|c|c|c|c|c|c|}
\hline \multicolumn{2}{|c|}{ Model } & \multicolumn{2}{|c|}{ Unstandardized Coefficients } & \multirow{2}{*}{$\begin{array}{l}\text { Standardized Coefficients } \\
\text { Beta }\end{array}$} & \multirow[t]{2}{*}{$t$} & \multirow[t]{2}{*}{$P$ value } & \multicolumn{2}{|l|}{ 95\% C.I. } \\
\hline & & B & SE & & & & Lower Bound & $\begin{array}{l}\text { Upper } \\
\text { Bound }\end{array}$ \\
\hline \multirow[t]{7}{*}{1} & Constant & 0.497 & 0.052 & & 9.646 & $<0.001^{*}$ & 0.394 & 0.600 \\
\hline & BMI & -0.002 & 0.002 & -0.181 & -1.394 & 0.169 & -0.006 & 0.001 \\
\hline & Hirsutism & 0.009 & 0.004 & 0.343 & 2.126 & $<0.05^{*}$ & 0.000 & 0.017 \\
\hline & TG & .000 & 0.000 & 0.112 & 0.925 & 0.359 & 0.000 & 0.001 \\
\hline & AFC & 0.006 & 0.005 & 0.217 & 1.251 & 0.216 & $0-.004$ & 0.016 \\
\hline & DEHA-S & -0.013 & 0.010 & -0.127 & -1.314 & 0.194 & -0.032 & 0.007 \\
\hline & HOMA-IR & -0.013 & 0.004 & -0.397 & -3.479 & $<0.001^{*}$ & -0.021 & -0.006 \\
\hline
\end{tabular}


Table 5 Logistic regression analysis evaluating the main independent variables associated with PCOS

\begin{tabular}{|c|c|c|c|c|c|c|c|c|}
\hline & & \multirow[t]{2}{*}{ B } & \multirow[t]{2}{*}{ S.E. } & \multirow[t]{2}{*}{ Wald } & \multirow[t]{2}{*}{$P$ value } & \multirow[t]{2}{*}{ odds } & \multicolumn{2}{|c|}{ 95\% C.I. } \\
\hline & & & & & & & Lower & Upper \\
\hline \multirow[t]{5}{*}{ Step 1} & MiRNA -320 & -12.252 & 3.326 & 13.572 & $<0.001^{*}$ & 0.000 & 0.000 & 0.003 \\
\hline & BMI & 0.210 & 0.112 & 3.552 & 0.059 & 1.234 & 0.992 & 1.536 \\
\hline & $\mathrm{LH}$ & 0.350 & 0.326 & 1.153 & 0.283 & 1.419 & 0.749 & 2.688 \\
\hline & Hirsutism & 0.097 & 0.211 & 0.214 & 0.644 & 1.102 & 0.730 & 1.665 \\
\hline & Constant & -1.146 & 2.834 & 0.164 & 0.686 & 0.318 & & \\
\hline
\end{tabular}

*Statistically significant $(P<0.05)$

Linear regression analysis with expression levels of miRNA - 320 as the dependent variable in PCOS groups

In the PCOS group, linear regression analysis revealed that only hirsutism and HOMA-IR was the main predictor of expression levels of miRNA - 320 among other clinical and laboratory biomarkers of PCOS (Table 4).

\section{Logistic regression analysis evaluating the main} independent variables associated with PCOS

Among the studied parameters, serum miRNA -320 expression levels were independently associated with PCOS, $P<0.001^{*}$ (Table 5).

\section{The accuracy of serum miRNA - 320 for diagnosis of PCOS} by ROC analysis

The power of serum miRNA -320 expression levels to diagnose PCOS among studied subjects was evaluated using ROC analysis. The AUC was 0.861 (95\% CI = $0.788-0.935)$ with sensitivity $=80 \%$, specificity $=97.5 \%$, and the cutoff values (0.7429), $P<0.001^{*}$, (Fig. 3$)$. The positive predictive value of serum miRNA -320 for diagnosis of PCOS was $35 \%$ and the negative predictive value was $80 \%$

The accuracy of serum ET-1for diagnosis of PCOS by ROC analysis

Regarding serum ET-1. The AUC was 0.882 (95\% CI = 0.804-0.959) with sensitivity $=91.7 \%$, specificity $=$ 99.3\%, and the cutoff values (5.66), $P<0.001^{*}$, (Fig. 4). The positive predictive value of serum ET-1for diagnosis of PCOS was $38.5 \%$ and the negative predictive value was $75 \%$

\section{Discussion}

Emerging evidence demonstrated that PCOS is a complex and heterogeneous endocrine condition characterized by hyperandrogenism and IR. Extensive data support a major role of IR as a common feature of PCOS, but not a diagnostic criterion of PCOS [12].

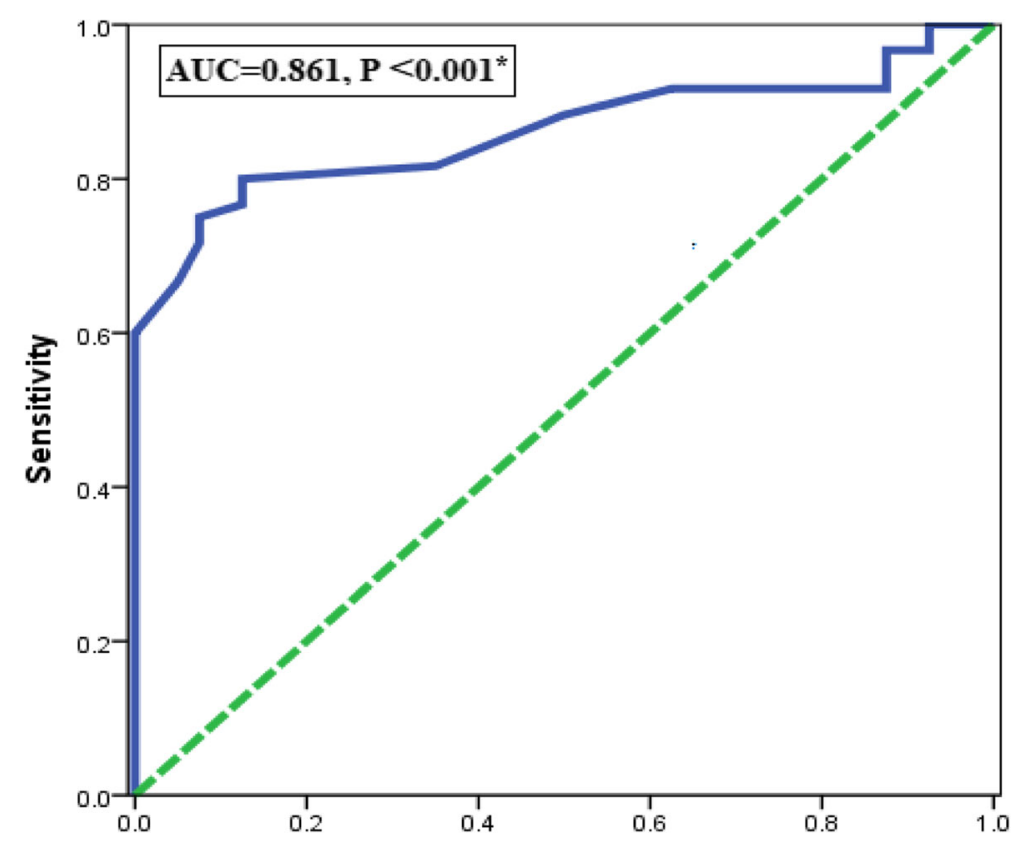

Fig. 3 Receiver operating characteristic (ROC) curve for serum miRNA - 320 expression level for prediction of PCOS 


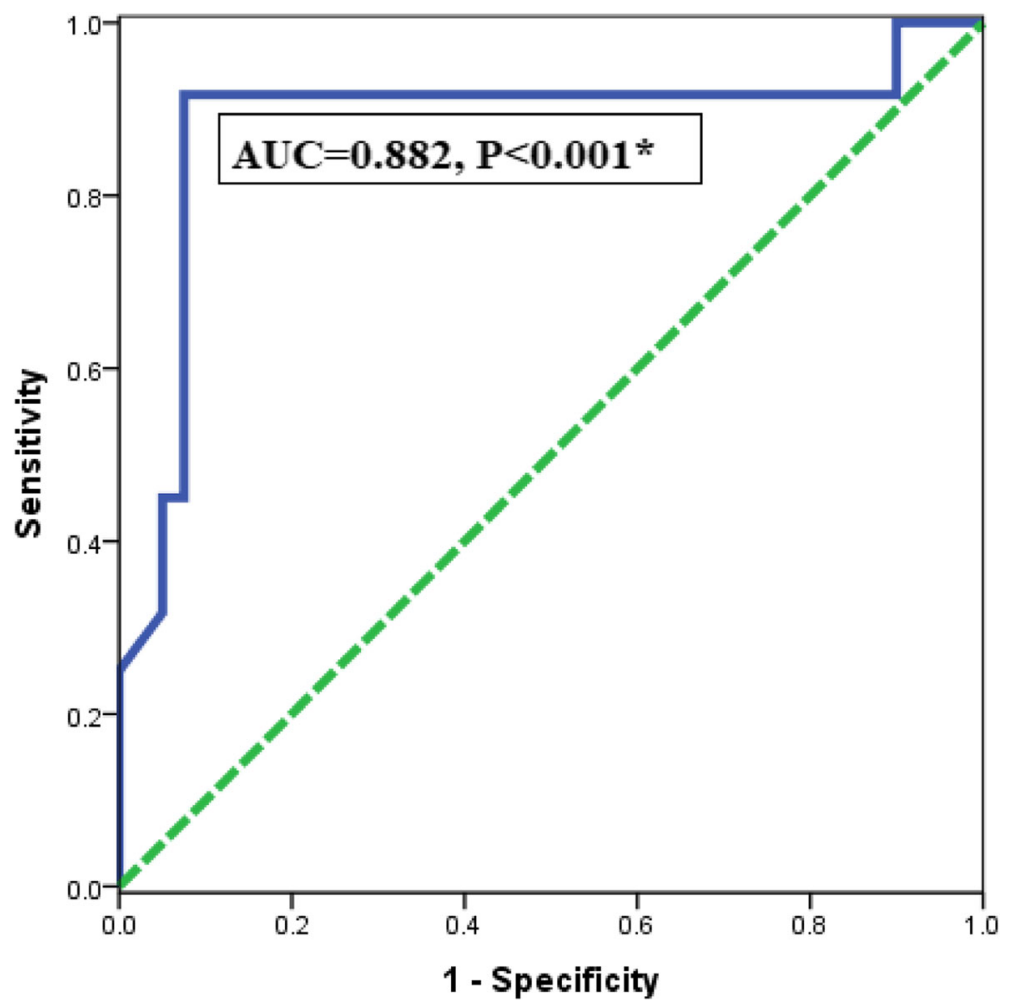

Fig. 4 Receiver operating characteristic (ROC) curve for serum ET-1 level for prediction of PCOS

In polycystic ovaries of anovulatory women, the precise molecular mechanisms that regulate antral follicular development remain unclear, omics studies have indeed demonstrated that the growth of these follicles is typically arrested before a mature follicle would be expected to ovulate [13].

MicroRNAs are endogenous, small, non-coding, single-stranded, regulatory RNA molecules, composed of 20-24 nucleotides [14]. There are intriguing reports suggested that miRNAs had a key role in follicular development and steroidogenesis among PCOS women. Moreover, emerging data have demonstrated that serum miRNAs could serve as a non-invasive biomarker for PCOS, as they have been shown to be stable and resistant to nuclease activity and are easy to detect [15].

ET-1 gene is regulated by different levels of expression, and regulation at the post-transcriptional level by miRNAs in particular; miR-320 which negatively regulates expression of ET-1. The aim of the current study was to investigate the role of miRNA- 320 as a noninvasive biomarker of PCOS and to evaluate its possible relationship with IR as well as clinic-morphological features of PCOS.

The results of the current study showed statistically significant elevations of cardiometabolic risk factors; insulin resistance and dyslipidemia, as well as phenotype characteristic of PCOS, compared to controls.
These results are in concordance with our previous studies [16-20].

The main finding of the present study is that the expression levels of miRNA - 320 in PCOS patients were significantly lower compared to the control group.

Our findings are in concordance with Long et al. they confirmed the downregulation of miR-320 in PCOS compared to controls [21].

We in this study attempted to pierce out the association between miRNA - 320 expression levels and IR in PCOS women, we detected that IR patients had significantly lower expression levels of miRNA -320 compared to PCOS women without IR.

In agreement with our results, Wang et al. found decreased the levels of miRNA in the serum of diabetic individuals as well as in the cardiac microvascular cells of diabetic rodents [22].

Similar to our result, a study conducted by Feng and Chakrabarti found decreased the expression of microRNA 320 in hyperglycemia [23].

Conflicting data have been reported expression levels of miRNA - 320 in various cohorts of PCOS, diabetic and obese patients as well as in rodents.in the study conducted by Ling et al. revealed that miR-320 expression levels in insulin-resistant adipocytes were upregulated [24]. 
Sang et al. revealed that miR-320 is expressed at significantly lower levels in the follicular fluid of PCOS patients than in healthy controls [25]. Also, Yuan and Tan confirmed in their study the downregulation of microRNA-320 expression in the ovarian tissue in the PCOS-IR group compared to the control group. Interestingly, they supposed that microRNA-320 could inhibit IR in patients with PCOS through IRS-1 regulating the ERK1/2 signaling pathway [26].

The study conducted by Yin et al. suggested that miR-320 expression levels increased in granulosa cells and associated with follicle proliferation and steroidogenesis of the ovary during ovary development [27].

The controversy of results could be due to differences in sample and methodology. In our study, we aimed to explore the noninvasive diagnostic biomarkers miR-320 so, we measure the miR-320 expression level in serum but most of the published studies estimated the miR-320 expression level in ovarian tissue as well as follicular fluid.

Regarding serum levels of ET-1, PCOS patients had significantly higher levels compared to the control group. Diamanti-Kandarakis et al. found that women with PCOS had elevated ET-1 levels compared with the age-matched control group [28].

Among the PCOS group, IR patients had significantly higher serum levels of ET-1 compared to PCOS women without IR. In agreement with our results, previous studies detected a higher level of ET-1 in patients with IR for example, obesity [29], diabetes mellitus [30], as well as impaired glucose tolerance [31].

The results presented herein are innovative; as this study performs a robust evaluation of serum miRNA 320 expression levels in regulating ET-1 level, we observed that there was a significantly negative correlation between serum miRNA -320 expression levels and ET-1.

Our data are in line with previous findings reporting that miR-320 negatively regulates expression of ET-1 [23].

Emerging evidence shows that MicroRNAs can regulate gene expression in both normal and disease states by direct targeting of the messenger RNA and inhibition of its translation to a protein, and/or by interfering with the epigenome [32] miRNA-320 act through its target ET-1 and inhibit IR in patients with PCOS through IRS-1 regulating the ERK1/2 signaling pathway and control pathways involved in follicular maturation [33].

\section{Acknowledgements}

Not applicable.
Availability of data and materials

Data available on demand.

\section{Authors' contributions}

NMR, YSS, WME, AAA, Md EBL, KFH, Md SY and AE. Ali collected patients' samples and clinical data. MA-MA prepared sample for laboratory investigations. NM. Rashad wrote the paper. Statistical analysis, interpretation of data and preparation the paper for submitting international was done by NM. Rashad. Critical revision of the manuscript was performed by all of the authors. All authors read and approved the final manuscript.

\section{Competing interest}

The authors declare that the research was conducted in the absence of anycommercial or financial relationships that could be construed as a potential conflict of interest.

In conclusion, we found that serum miR-320 expression level were lower in PCOS patients compared to controls, in particular, PCOS women with IR. Moreover, it was negatively correlated to its target gene; ET-I as well as FSI, HOMA-IR, PCOS phenotype; hirsutism score, ovarian volume, and AFC .we hypothesis that serum miR-320 expression level could be a non-invasive biomarker of PCOS and further study indeed to assess its potential therapeutic role as suggested by previous experimental studies.

\section{Consent for publication}

Not applicable.

\section{Competing interests}

The authors declare that they have no competing interests.

\section{Publisher's Note}

Springer Nature remains neutral with regard to jurisdictional claims in published maps and institutional affiliations.

\section{Author details}

${ }^{1}$ Internal Medicine Department, Faculty of Medicine, Zagazig University, Zagazig, Egypt. ${ }^{2}$ Clinical Pathology Department, Faculty of Medicine, Zagazig University, Zagazig, Egypt. ${ }^{3}$ Obstetrics and Gynecology Department, Faculty of Medicine, Zagazig University, Zagazig, Egypt.

Received: 7 February 2019 Accepted: 16 April 2019

Published online: 07 May 2019

\section{References}

1. Diamanti-Kandarakis E. Polycystic ovarian syndrome: pathophysiology, molecular aspects, and clinical implications. Expert Rev Mol Med. 2008;10:e3.

2. Diamanti-Kandarakis E. Insulin resistance in PCOS. Endocrine. 2006;30:13-7.

3. Dunaif A. Insulin resistance and the polycystic ovary syndrome: mechanism and implications for pathogenesis. Endocr Rev. 1997;18:774-800.

4. Heneghan HM, Miller N, Kerin MJ. Role of microRNAs in obesity and the metabolic syndrome. Obes Rev. 2010;11:354-61.

5. Fernandez-Valverde SL, Taft RJ, Mattick JS. MicroRNAs in beta-cell biology, insulin resistance, diabetes, and its complications. Diabetes. 2011;60:1825-31.

6. Carletti MZ, Christenson LK. MicroRNA in the ovary and female reproductive tract. J Anim Sci. 2009:87:E29-38.

7. Xue Y, Ly J, Xu P, Gu L, Cao J, Xu L, et al. Identification of microRNAsand genes associated with hyperandrogenismin the folicular fluid of women with polycystic ovary syndrome. J. Cell. Biochem. 2018;119(5):3913-3921.

8. Tadano T, Kakuta Y, Hamada S, Shimodaira Y, Kuroha M, Kawakami Y. MicroRNA-320 family is downregulated in colorectal adenoma and affects tumor proliferation by targeting CDK6. World J Gastrointest Oncol. 2016;8(7):532-42. https://doi.org/10.4251/wjgo.v8.i7.532.

9. Flammer J, Konieczka K. Retinal venous pressure: the role of endothelin. EPMA J. 2015:6:21.

10. Li C, Sun Y, Liu B. The relationship between endothelin and tumor. Foreign Med Oncol Branch. 2003;30:360-2.

11. The Rotterdam ESHRE-ASRM-Sponsored PCOS Consensus Workshop Group. Revised 2003 consensus on diagnostic criteria and long-term health risks related to polycystic ovary syndrome (PCOS). Hum Reprod. 2004;19:41-7.

12. Mukherjee $\mathrm{S}$, Maitra A. Molecular and genetic factors contributing to insulin resistance in polycystic ovary syndrome. Indian J Med Res. 2010;131:743-60. 
13. Willis DS, Watson H, Mason HD, Galea R, Brincat M, Franks S. Premature response to luteinizing hormone of granulosa cells from anovulatory women with polycystic ovary syndrome: relevance to mechanism of anovulation. J Clin Endocr Metab. 1998:83:3984-399.

14. Ambros V. MicroRNAs: Tiny regulators with great potential. Cell. 2001:107:823-6. https://doi.org/10.1016/S0092-8674(01)00616-X.

15. Zampetaki A, Kiechl S, Drozdov I, Willeit P, Mayr U, Prokopi M, Mayr A, Weger S, Oberhollenzer F, Bonora $E$, et al. Plasma microRNA profiling reveals loss of endothelial MiR-126 and other microRNAs in type 2 diabetes. Circ Res. 2010;107:810-7. https://doi.org/10.1161/CIRCRESAHA. 110.226357.

16. Amal S, Zidan HE, Rashad NM, Abdelaziz AM, Harira MM. Association between genes encoding components of the leutinizing hormone/ luteinizing hormone-choriogonadotrophin receptor pathway and polycystic ovary syndrome in Egyptian women. IUBMB Life. 2016;68(1):23-36.

17. Rashad NM, El-Shal AS, Abdelaziz AM. Association between inflammatory biomarker serum procalcitonin and obesity in women with polycystic ovary syndrome. J Reprod Immunol. 2013;97(2):232.

18. Rashad NM, Abd-Elrahman MA, Amal S, Amin Al. Serum visfatin as predictive marker of cardiometabolic risk in women with polycystic ovary syndrome. Middle East Fertil Soc J. 2018; https://doi.org/10.1016/j.mefs.2018. 04.008.

19. Rashad NM, Amin Al, Ali AE, Soliman MH. Influence of obesity on soluble endoglin and transforming growth factor b1 in women with polycystic ovary syndrome. Middle East Fertil Soc J. 2018;23(4):418-24.

20. Amal S, Shalaby SM, Aly NM, Rashad NM, Abdelaziz AM. Genetic variation in the vitamin D receptor gene and vitamin D serum levels in Egyptian women with polycystic ovary syndrome. Mol Biol Rep. 2013;40(11):6063-73.

21. Long W, Zhao C, Ji C, Ding H, Cui Y, Guo X, Shen R, Liu J. Characterization of serum MicroRNAs profile of PCOS and identification of novel noninvasive biomarkers. Cell Physiol Biochem. 2014;33:1304-15 https://doi.org/ 10.1159/000358698.

22. Wang XH, Qian RZ, Zhang W, Chen SF, Jin HM, Hu RM. MicroRNA-320 expression in myocardial microvascular endothelial cells and its relationship with insulin-like growth factor- 1 in type 2 diabetic rats. Clin Exp Pharmacol Physiol. 2009;36(2):181-8.

23. Feng B, Chakrabarti S. miR-320 regulates glucose-induced gene expression in diabetes. ISRN Endocrinol. 2012;2012:549875.

24. HY L, Ou HS, Feng SD, Zhang XY, Tuo QH, Chen LX, Zhu BY, Gao ZP, Tang CK, Yin WD, Zhang L, Liao DF. CHANGES IN microRNA (miR) profile and effects of miR-320 in insulin-resistant 3T3-L1 adipocytes. Clin Exp Pharmacol Physiol. 2009 Sep;36(9):e32-9. https://doi.org/10.1111/j.1440-1681.2009. 05207.x.

25. Sang $Q$, Yao $Z$, Wang $H$, Feng $R$, Wang $H$, Zhao $X$, Xing $Q$, Jin $L$, He $L$, Wu L, Wang L. Identification of microRNAs in human follicular fluid: characterization of microRNAs that govern steroidogenesis in vitro and are associated with polycystic ovary syndrome in vivo. J Clin Endocrinol Metab. 2013;98(7):3068-79. https://doi.org/10.1210/jc.2013-1715 Epub 2013 May 10.

26. Yuan WN, Tan L. MicroRNA-320 inhibits insulin resistance in patients with PCOS through regulating ERK1/2 signaling pathway. Biomed Res. 2017:28(11):4946-9.

27. Yin $M$, Wang $X$, Yao G, Lu M, Liang M, Sun Y, Sun F. Transactivation of miR320 by miR-383 regulates granulosa cell functions by targeting E2F1 and SF-1*. J Biol Chem. 2014. https://doi.org/10.1074/jbc.M113.546044.

28. Diamanti-Kandarakis E, Spina G, Kouli C, Migdalis I. Increased Endothelin-1 levels in women with polycystic ovary syndrome and the beneficial effect of metformin therapy. J Clin Endocrinol Metabol. 2001;86(10):4666-73 https://doi.org/10.1210/jcem.86.10.7904.

29. Ferri C, Bellini C, Desideri G, et al. Circulating endothelin-1 levels in obese patients with the metabolic syndrome. Exp Clin Endocrinol Diabetes. 1997;105(Suppl 2):38-40.

30. Ferri C, Bellini C, Desideri G, Baldoncini R, De Siati L, Santucci A. Elevated plasma endothelin-1 levels as an additional risk factor in non-obese essential hypertensive patients with metabolic abnormalities. Diabetologia. 1997:40:100-2.

31. Caballero AE, Arora S, Saouaf R, et al. Microvascular and macrovascular reactivity is reduced in subjects at a risk for type 2 diabetes. Diabetes. 1999:48:1856-62.
32. Saetrom P, Snove O Jr, Rossi JJ. Epigenetics and microRNAs. Pediatr Res. 2007;61(5 Pt 2):17R-23R. https://doi.org/10.1203/pdr.0b013e318045760e.

33. Santonocito M, Vento M, Guglielmino MR, Battaglia R, Wahlgren J, Ragusa $\mathrm{M}$, et al. Molecular characterization of exosomes and their microRNA cargo in human follicular fluid: bioinformatic analysis reveals that exosomal microRNAs control pathways involved in follicular maturation. Fertil Steril. 2014;102(6):1751-U590. https://doi.org/10.1016/j.fertnstert.2014.08.005.
Ready to submit your research? Choose BMC and benefit from:

- fast, convenient online submission

- thorough peer review by experienced researchers in your field

- rapid publication on acceptance

- support for research data, including large and complex data types

- gold Open Access which fosters wider collaboration and increased citations

- maximum visibility for your research: over $100 \mathrm{M}$ website views per year

At BMC, research is always in progress.

Learn more biomedcentral.com/submissions 